\title{
Earth Construction Durability: In-Service Deterioration of Compressed and Stabilized Earth Block (CSEB) Housing in Algeria
}

\author{
Adel. Benidir, M'hamed. Mahdad and Ahmed. Brara \\ National Center of Integrated Studies and Research on Building Engineering (CNERIB), 16201, \\ Souidania, Algiers, Algeria, abenidir.cnerib@gmail.com
}

\begin{abstract}
The present work deals with a unique in-service valuation of CSEB structures in Algeria. The inspection tries to bring out the impact of long time exposure under different and opposite climate and micro-seismic contexts. The diagnosis methodology is inspired by the approach largely adopted for the rehabilitation of traditional architecture. It involves the compilation of the previous survey reports, visual inspection of the structures, in-situ and laboratory tests to assess the residual CSEB mechanical properties. The CSEB constructions are located in the coastal north and the desertical south part of Algeria and were exposed respectively to a long-term Mediterranean and Saharian climate. The results of the investigation show that the CSEB in the construction located in the northern region is increasingly altered by the humidity. As the relative humidity rises, the fouling layers grow over some level. The surface pitting which is the consequence of long exposure to the wetting/drying cycles is also observed. The outer surfaces of the walls were honeycombed which reduce drastically the block resistance against the abrasion test. In some cases, differential erosion appears in the front of the walls, which indicates that the alteration does not proceed at the same rate from one area of the block to the other. However, owing to highly cementitious mortar used to join the earth blocks, the edges and corners remain unchipped. In the southern region where the arid climate dominating, the degradation of the CSEB is less prone to water attack but roughly exposed to the effect of the winddust frequent in this region and to the unawareness of the population. The paper presents also some recommendations to improve the earth construction durability with CSEB technique.
\end{abstract}

Keywords: Earth Blocks, Durability Valuation, Weather Exposure.

\section{Introduction}

Among the eco-friendly building materials, the Stabilized and Compressed Earth Block (CSEB) is considered the most promising. Hence, improving the sustainability of this material deserves more attention and study. If the durability at the scale of the unit and the structural element in CSEB (Guettala et al., 2006), the scientific literature is prolific, it is not the same for constructions in the field with this material. Regular monitoring of CSEB building in the aim to assess the durability of the materials has received little formal research. The returns are generally based on a review or reported after a large building degradation or collapse. For instance, the document elaborated by Arandara and Jayasinghe (2007) on the durability of the CSEB construction gives prominent insight. The project focused on the report of the degradations observed on a group of 50 houses, $59 \%$ of which were built in Matara (Sri Lanka) with stabilized earth blocks. This appraisal shows that the pathologies identified are mainly due to climatic factors, in particular, heavy rainfall and wind. It has been observed the appearance of water absorption by capillarity caused by the inappropriate stabilization of the 
earth blocks. In addition, more erosion of the walls composed with the weakly stabilized block was noticed.

Based on previous experience, in 1949, India launched a program of construction of several hundred housing units (Bangalore), in which earth blocks manually compressed and stabilized with $5 \%$ of the cement was used. Some of these houses are still occupied to this day. Certain blocks from the demolished buildings were found to have a wet compressive strength of the order of 1.5 MPa. On the African continent, the survey reported by Oppong and Badu (2012) revealed that the walls (built with CSEB) exhibit considerable damages due to their exposure to high water absorption in Ghana. The recurring cycles of wetting/drying have inevitably caused their cracking alterations. Moreover, the blocks have been found to have low tensile strength and abrasion. In Uganda, where the projected housing backlog by the year 2000 was estimated at 3 million dwellings, an inventory of CSEB structures has been achieved by Kerali (2017). The author confirmed that in humid tropical areas, rainfall and temperature variations can adversely affect the performance of a block exposed to the elements. It was further related to the extensive appeal to this kind of construction in low income urban and rural areas.

\section{Methods}

The chosen diagnosis methodology is inspired by the one recommended by the Réhabimed guide (RéhabiMed, 2007) concerning the approach to be followed for the rehabilitation of

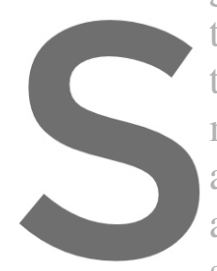
traditional architecture.

the present context, multidisciplinary studies, and and defines their nature according to the state structural stability or ii) The

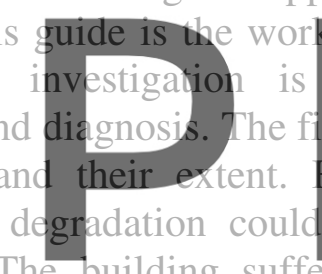
pathologies. The second stage considers all historical and documentary studies that lead to the

delimits and locates the factors of degradations. Finally, the diagnosis is developed following the anaiysis of the whole collected information to determine the causes of the disorders in order to define in fine the appropriate remedies. The diagnosis is supported by the analysis of the recorded climatic and seismic activity data of each region over the last decades.

Furthermore, laboratory and in situ tests have been performed to assess the block residual mechanical properties with both destructive (crushing) and non-destructive tests (mass rebound, abrasion). The compressive test using an universal press were extracted from the cornice and acroterion and replaced by new CSEBs in the building. The in situ tests rely on the use of pendulum sclerometer, consisting of the measurement the return of the rebound of a mass impacting a vertical surface. Abrasion tests has been performed on the block at different locations of the wall. Using a steel brush, the technique undertakes surface brushing along the entire length of the block for about a minute, which equals 30 round trips.

\section{Location of the Sites, CSEB Buildings and Climate Environment}

The figure 1 shows the geographic locations of the different sites assigned to the earth constructions studied throughout this investigation program. 


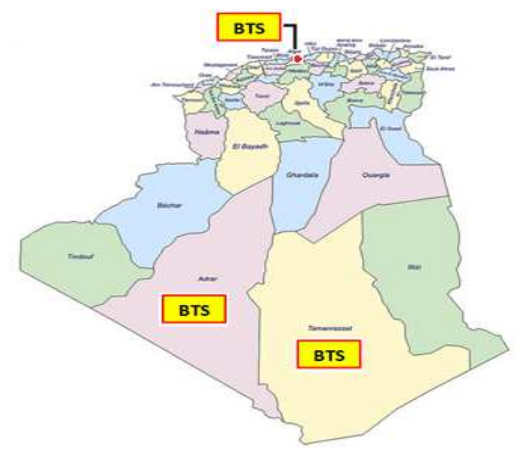

Figure 1. Geographic locations of sites.

The buildings are ground dwellings except in one residential site situated in the north region (see figure 2.c). The stabilisation of the earth blocs are both chemical and mechanical. The portion of cement exceeds $7 \%$ and could be in some places more than $10 \%$. The second stage of stabilisation relies on reducing the pores volume by applying a compactive effort with at least $7 \mathrm{MPa}$ of stress, using as a matter of fact a manual or a hydraulic semi-automatic press. This moulding pressure raises the bulk density of the block as it improves the block performance against the water runoff erosion phenomenon. The cure process involves a storage of the blocks under roofing or hat for 28 days. It requires also a light watering for a week with a wrap. The dimensions of the blocks used in these constructions are different from one site to another. For instance, the dinsensions of the blocks manufactured and used to build the first bioclimatic prototype at Souidania in 1984 (Algiers, figure 2.a) are $250 \mathrm{~m}$ $125 \mathrm{~mm}$ in width and $70 \mathrm{~mm}$ in height. In 2007. length, $140 \mathrm{~mm}$ in width and $90 \mathrm{~mm}$ in height were prepared to construct bioclimatic prototype (figure 2.b). Over all the surveyed houses, the earth blocks

except in the site of Beni Messous where compressed earth hollow blocks were used.

Register for free at https//www.scipedia.com to download the version without the watermark

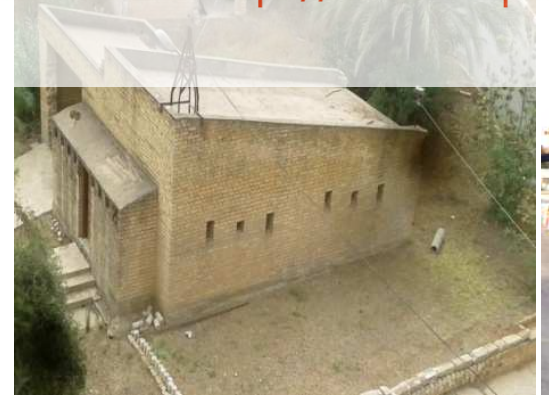

a) Bioclimatic prototype Souidania (1984, Algiers)

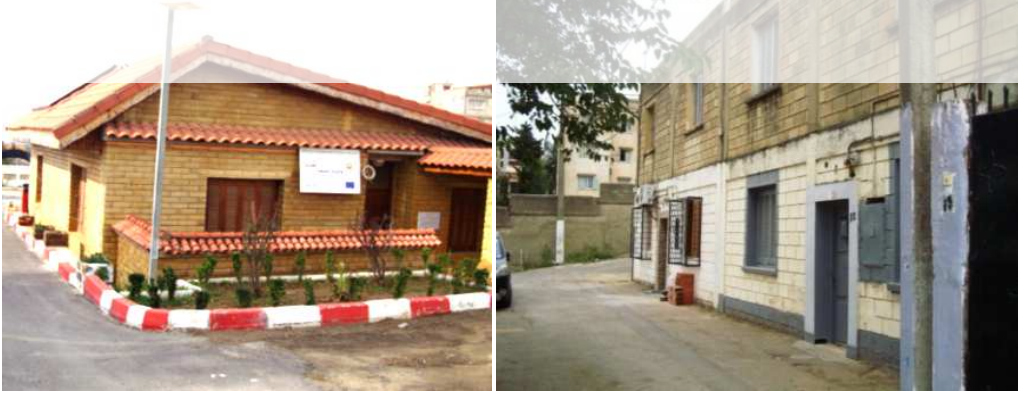

b) Bioclimatic prototype Souidania (2007, Algiers) c) Houses at Beni Messous (1987, Algiers)

Figure 2. Load bearing soil-cement block residential building in the northern region. 


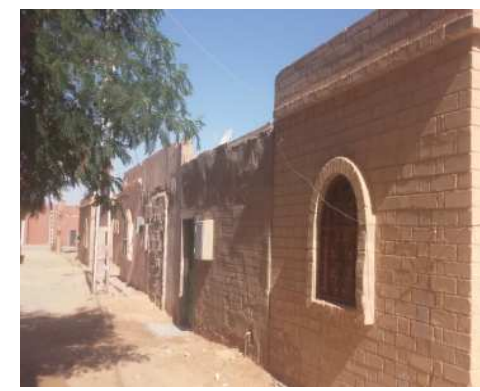

a) Adrar

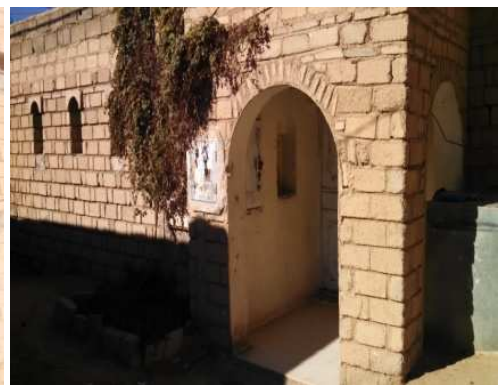

b) Sersouf (Tamanrasset )

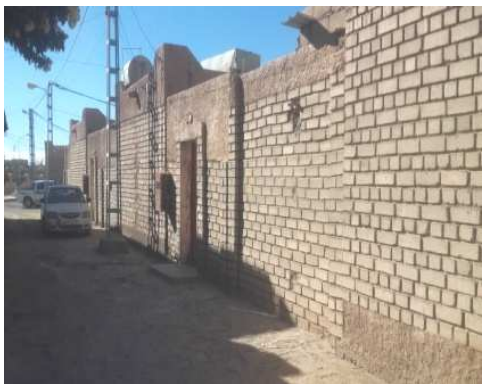

c) Mouflon (Tamanrasset)

Figure 3. Load bearing soil-cement block residential building in the northern region.

The appraisal concerns three departments (Wilaya): Algiers (Capital), Adrar and Tamanrasset. The temperature, the relative humidity and the accumulated rainfall amounts referring to these regions are respectively depicted in figure 4, 5 and 6. In summer, the maximum temperature (not the peak) reaches $44{ }^{\circ} \mathrm{C}$ in Tamanrasset and $33{ }^{\circ} \mathrm{C}$ in Algiers. The relative humidity is up $78 \%$ in the north and less than $40 \%$ in the south. The maximum accumulated rainfall amounts in the coastal region is around $1000 \mathrm{~mm}$ where the value of this parameter is extensively in decrease in the south region.
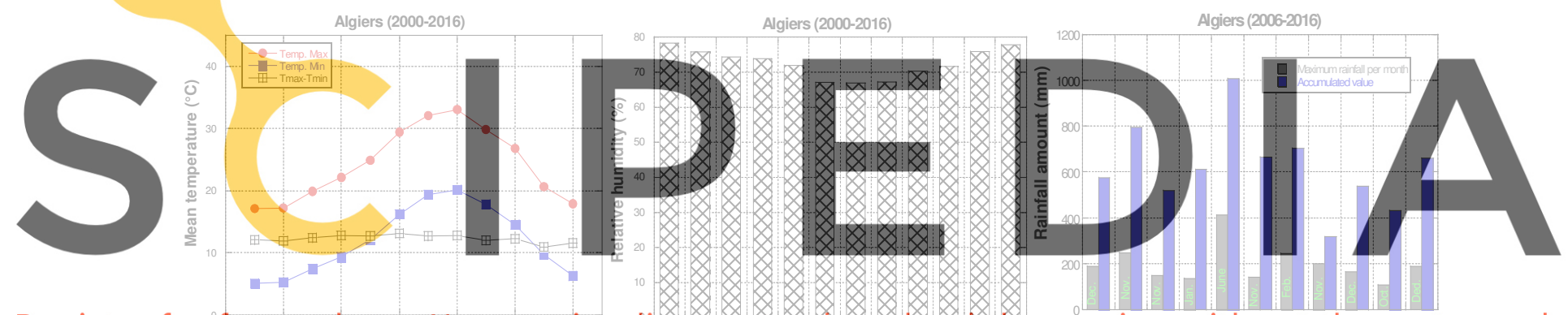

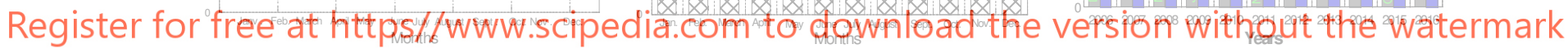

(c)

Figure 4. Climatic parameters in Algiers department, a) temperature, b) relative humidity c) rainfall amounts.

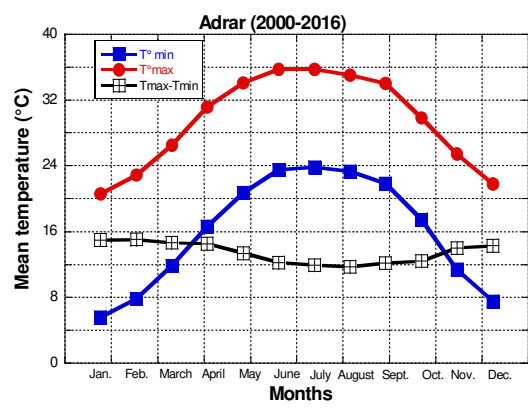

(a)

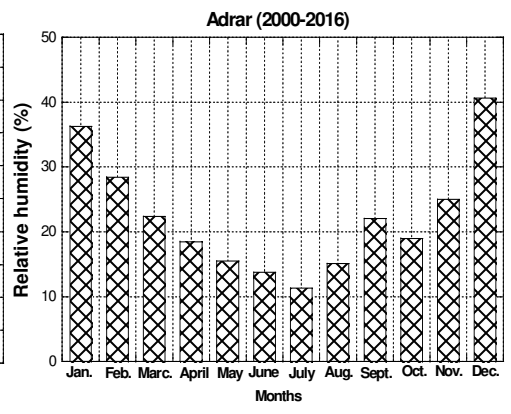

(b)

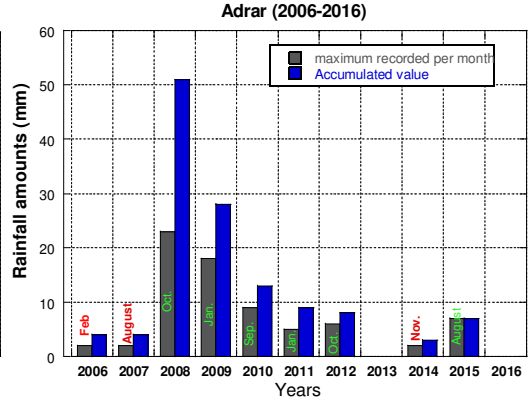

(c)

Figure 5. Climatic parameters in the department of Adrar, a) temperature, b) relative humidity c) rainfall amounts. 


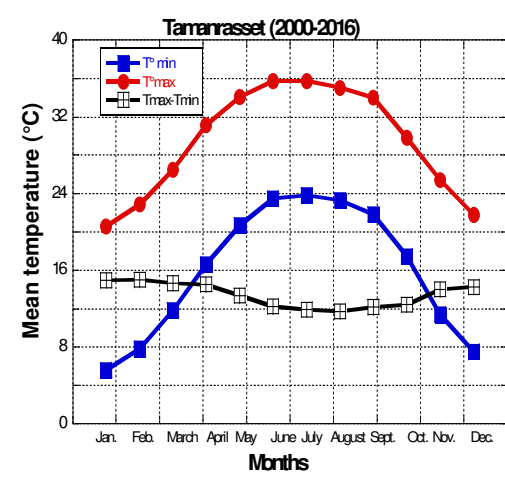

(a)

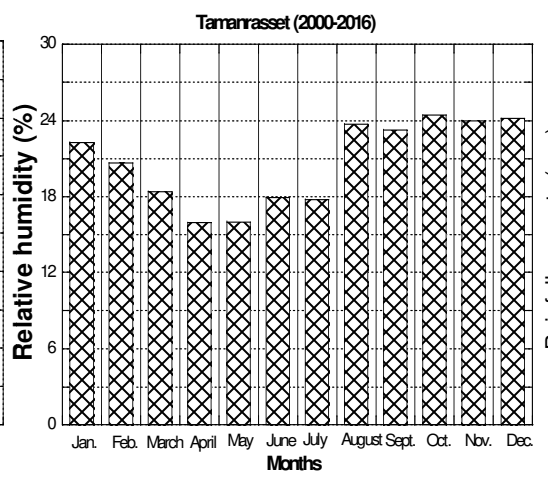

(b)

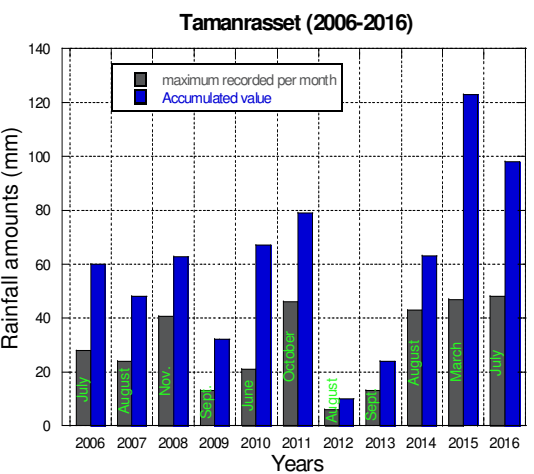

(c)

Figure 6. Climatic parameters in the department of Tamanrasset, a) temperature, b) relative humidity c) rainfall amounts.

\section{Resullts}

Ageing-related pathologies observed in stabilized earth constructions (CSEB) in the coastal northern region are mainly caused by weather element. Water (rain, humidity) is considered as the main cause of damage. For instance, the abundant rain in the northern region has three main effects:

i) The direct and repeated impact of the violent rain alters the surface of the external elements and causes :

ii) The flow of the blocks which thereb

iii) The splashing and infiltration

on the ground, awning, weathering, crumbling and digging.

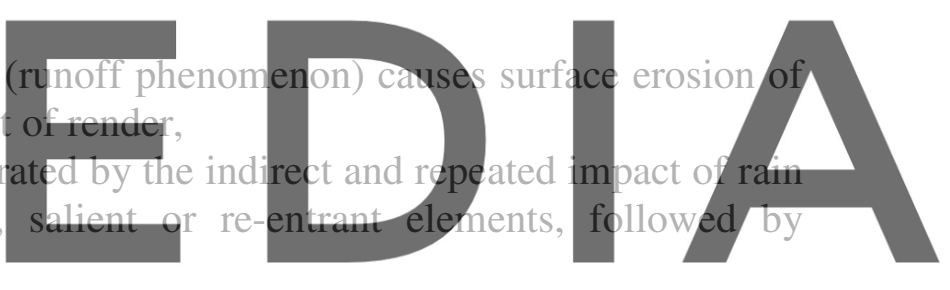

As depicted on figure 7.a, the crumbling due to the impact of splashing attains generally

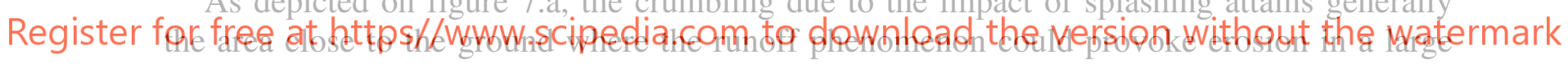
surface above the base (figure 7.b).

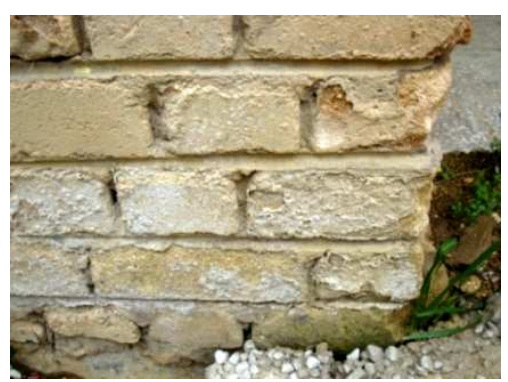

a) Splashing

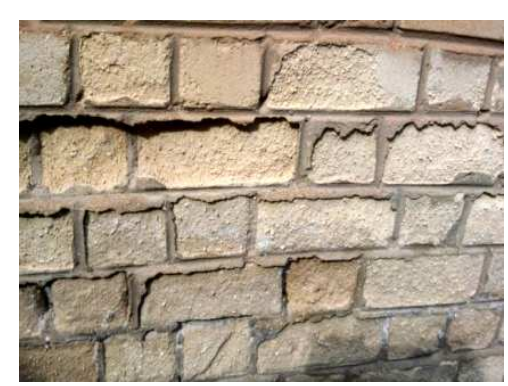

b) Surface erosion

Figure 7. Impact of the mechanical action of the rainwater.

The inattention on removing the element likely to cause seasonal variations in humidity in particular the vegetation near the building participate actively on the development of humid pathology (figure 8). 


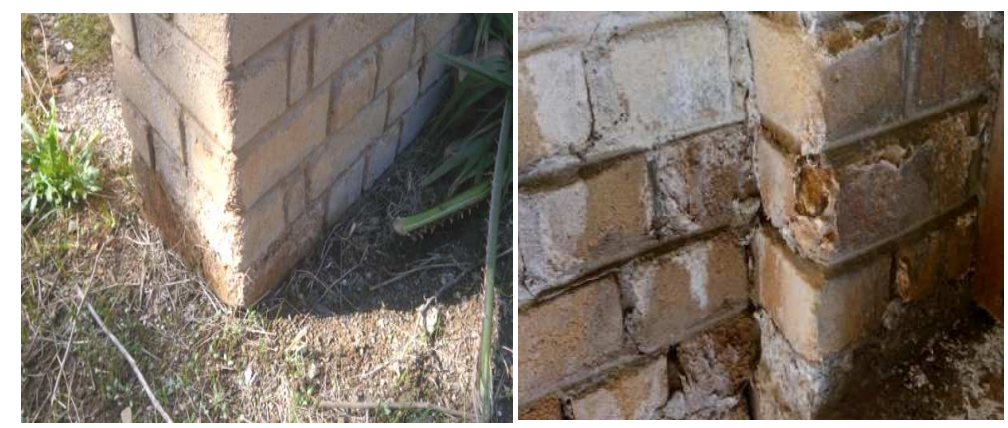

Figure 8. Degradation observed in the north region (humid pathology).

Furthermore, due to the high humidity rate, the pollution released in the air is fixed on the structures' external envelopes by dirtying the contact surfaces and favouring biological colonization (figure 9).

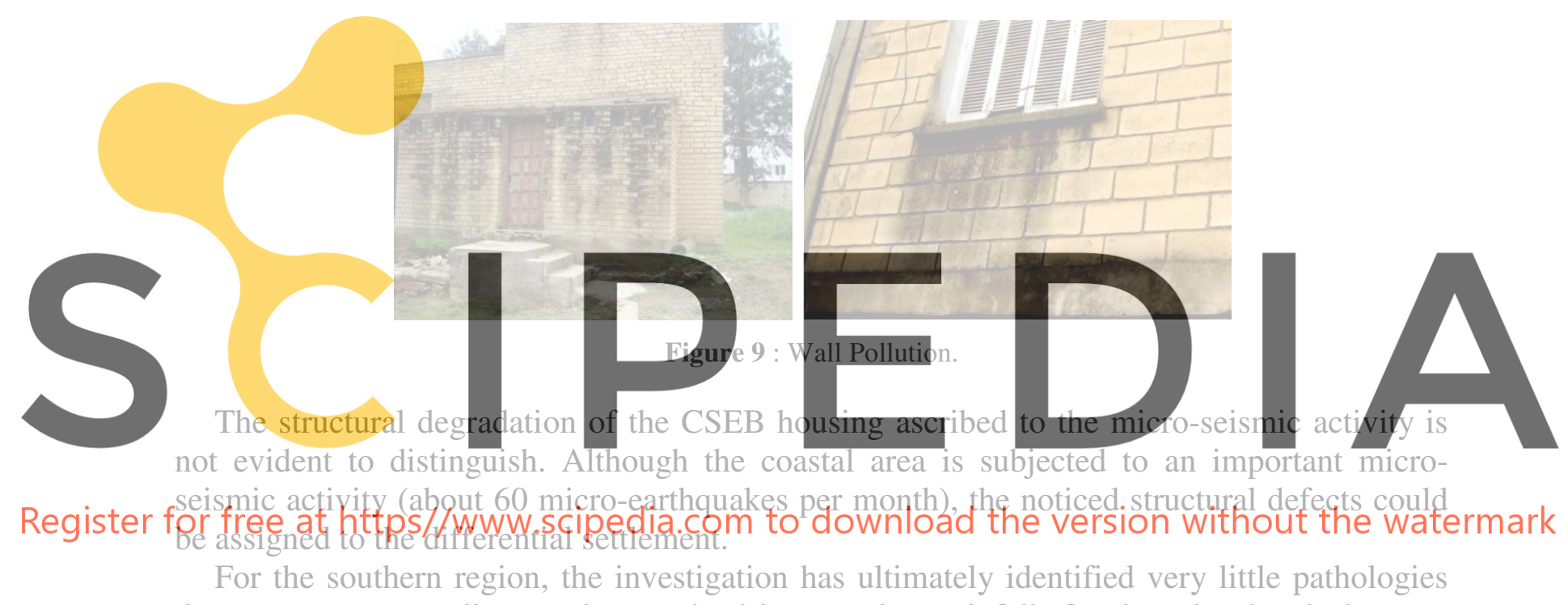

due to exposure to climate, characterized by very low rainfall. On the other hand, the very frequent winds activity in this region has a stronger mechanical action when they carry suspended particles, such as the sands. The most common defects observed included: surface roughening, erosion and surface pitting. However, the inspection in the North and South regions has highlighted significant degradation resulting from poor design, production and implementation of the blocks, as well as others due to human intervention such as undertaking fitting out works or installation of air conditioning equipments. 

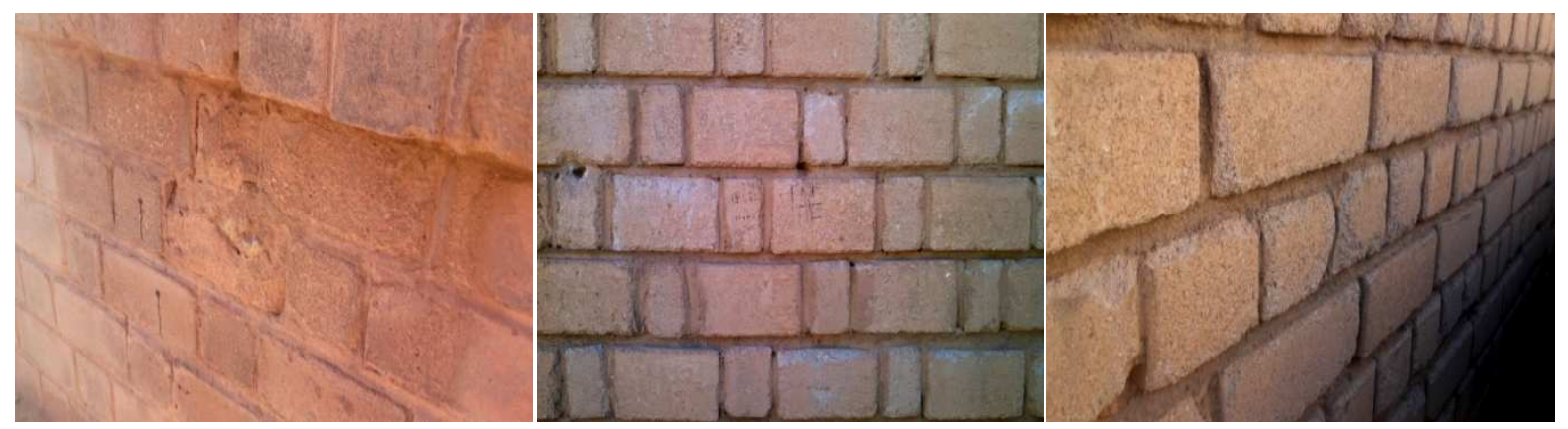

Figure 10. Direct impact of the mechanical action of the wind.

\section{Conclusions and Contribution}

In this contribution, an evaluation of the in-service earth housing degradation in Algeria is reported. The investigation consists of an in-field visit including visual inspections supported by in situ and laboratory tests on CSEB. The visited earth constructions are long-time exposed to varied micro-seismic and climate contexts. In the coastal region where the high rainfall frequency and important humidity rate prevails, the CSEB constructions defects included: black fouling, due to pollution and biological colonization, efflorescence, detachment of render and erosions caused by the effects of whipping rains. On the one hand, the housing experiencing arid climate condition, the blocks are less prone to humid pathology. The observed defects concern surface roughening and pitting. On the other hand, the degradation
caused by the inhabitant unawareness adversely affects the performance of the blocks. From the analysis of the degrada

to improve the durabilit

- Maintenance of the te
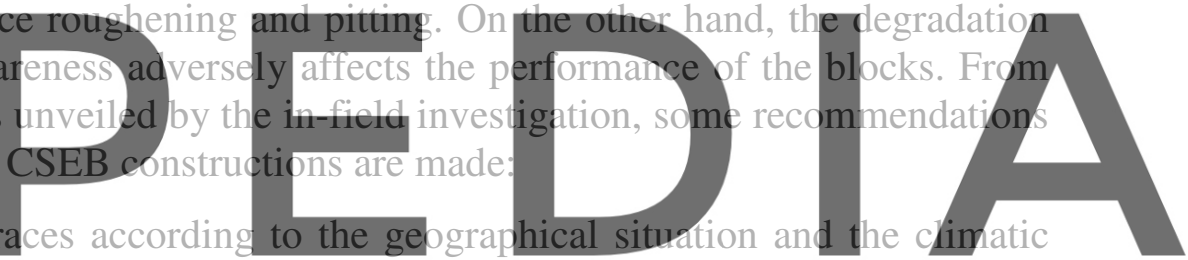
conditions.

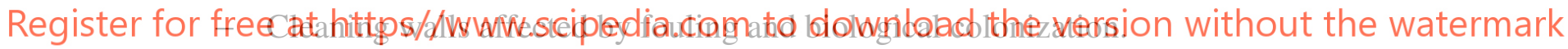

- Checking the correct drainage of rainwater (avoid stagnation of water) to provide a good circulation and evacuation of the collected rainwater.

- Removing the element likely to cause seasonal variations in humidity in particular the vegetation near the building.

- Elevating the base, putting a sufficient roof overhang or installing an anti-capillary barrier especially in the North region.

- Resorting to the earth construction guide in the selection of the soil nature and the process of stabilization.

- Installing a windbreak and / or choosing an appropriate orientation of the structure minimizing the direct exposure to the winds. 


\section{ORCID}

Adel Benidir : https://orcid.org/0000-0002-7645-1903

M'hamed Mahdad : https://orcid.org/0000-0002-6957-0648

Ahmed Brara : not available.

\section{References}

Arandara, K. P. and Jayasinghe, C. (2007). Identification of Durability Problem in Earth Building, ENGINEER. Journal of the Institution of Engineers, Sri Lanka, Vol. xxxx. no.04, Sri Lanka, pp.14-21. doi.org/10.4038/engineer.v52i2.7352

Guettala, A. Abibsi, A and H. Houari. (2006). Durability study of stabilized earth concrete under both laboratory and climatic conditions exposure, Construction and Building Materials, 20, 119-127. doi:org/10.1016/j.conbuildmat.2005.02.001

Kerali G.A. (2017). Exposure condition survey and measurement of defects in compressed stabilized earth block structures in uganda. International Journal of Recent Innovation in Engineering and Research. Volume: 02 Issue: 08 .

Oppong, R. A. and Badu, E. (2012). Evaluation of stabilised-earth block for housing provision and construction Ghana. Journal of Science and Technology, Vol. 32, No. 2, pp 104-118. doi.org/10.4314/just.v32i2.12
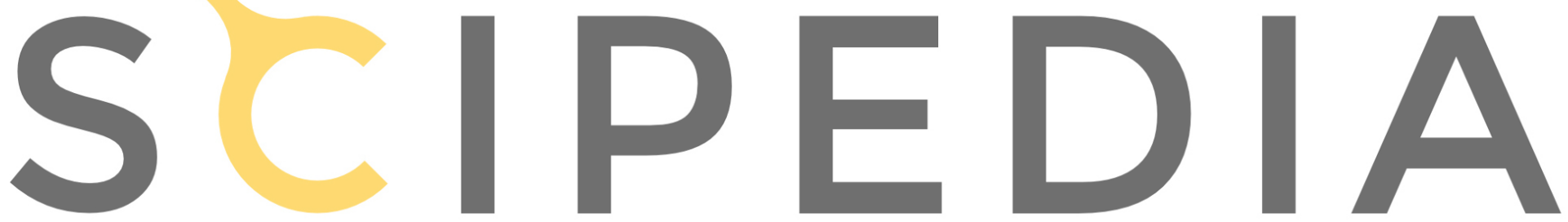

Register for free at https//www.scipedia.com to download the version without the watermark 